\title{
TELEFONIA PÚBLICA A CARTÃO INDUTIVO - UMA SOLUÇÃO ADAPTADA À REALIDADE BRASILEIRA
}

\author{
Marcos Assano \\ CPqD - Telebrás \\ Rodovia Campinas Mogi-Mirim Km 118,5 (SP 340) \\ CEP: 13088 - 061 - Campinas - SP \\ Telefone: (019) 789-6707 \\ Fax: (019) 789-6490
}

\begin{abstract}
Resumo: Seguindo a tendência mundial de uso de cartões em telefones públicos, o Brasil adotou o sistema indutivo, uma tecnologia de baixo custo e desenvolvido para operar sob as características peculiares da sociedade brasileira. Este trabalho tem como objetivo apresentar os motivadores para o desenvolvimento do Sistema de Telefonia Pública a Cartão Indutivo bem como a tecnologia envolvida neste desenvolvimento. Também são descritas a experiência de implantação deste sistema no Brasil e suas consequiências.
\end{abstract}

Abstract Following the worldwide trend of using cards in public telephones, Brazil has adopted the inductive system, a low cost technology, developed to operate under the particular characteristics of the Brazilian society. This paper presents the incentives for the development of an inductive card based public telephony system and the technology related to this development. The introduction of this system in Brazil and its consequences are also described.

Palavras chave: Telefonia Pública, Cartões Telefônicos, Tecnologia Indutiva.

\section{INTRODUÇÃO}

Em países em desenvolvimento, o oferecimento do serviço de telefonia pública a custos reduzidos é vital por uma questão social, uma vez que a grande maioria da população nāo tem facilidade de acesso a outros serviços de telecomunicações. Nestes países, a própria telefonia pública se mostra deficiente devido aos restritos investimentos neste setor e ao alto custo operacional deste $\vdots=-\because \xi 0$.

No Brasil, até o início da introdução da tecnologia indutiva, o total de telefones públicos baseados em fichas telefônicas ultrapassava o montante de 250 mil aparelhos. Altos custos operacionais, causados principalmente pelo processo de coleta e distribuição de fichas ou pela necessidade de manutenção freqüente de aparelhos vítimas do vandalismo, dificultam o oferecimento de um serviço mais abrangente que atinja áreas onde vivem populações de baixo poder aquisitivo, normalmente periferias e áreas mais afastadas dos grandes centros urbanos, de difícil acesso.

A expansão da telefonia pública torna-se portanto um importante instrumento de democratização dos serviços de telecomunicações, permitindo que uma parcela maior da população tenha acesso a eles. Neste contexto, o Brasil passa a substituir seu sistema de telefonia pública baseada em fichas telefônicas, passando para um sistema mais moderno, mais eficiente, mais confiável, de fácil gerenciamento e que proporcione uma redução dos custos atualmente envolvidos: o Sistema TP-Cartão.

O Sistema TP-Cartão, além de reduzir os custos operacionais, flexibiliza também a introdução de novos serviços seja no aparelho telefônico, seja nos cartōes, leitoras ou no Centro de Supervisão Automatizada - CSA -, permitindo a expansão da planta de telefones públicos com maior grau de satisfação do usuário.

Este trabalho tem como objetivo apresentar os motivadores para o desenvolvimento do sistema TPCartão bem como a tecnologia envolvida neste desenvolvimento. Também são descritas a experiência da implantação do sistema TP-Cartão no Brasil e os resultados obtidos, destacando-se futuros serviços que a mudança de tecnologia proporciona.

\section{A REALIDADE BRASILEIRA}

No Brasil, a idéia de migração da tecnologia de telefones públicos baseados em fichas para telefones públicos baseados em cartões segue a tendência mundial. Entretanto, as diferenças econômicas e culturais entre os países acarreta em diferentes modos de prestação do serviço de telefonia pública. $O$ telefone público a cartão brasileiro surgiu a partir de necessidades específicas da sociedade brasileira:

- O baixo custo da telefonia pública, que tem $o$ relevante aspecto social, possibilitando o acesso da população de baixa renda (hoje mais de $50 \%$ da populaçāo) aos serviços de telecomunicaçōes. $\mathrm{O}$ baixo custo de produção dos cartões é fundamental, possibilitando a comercialização de cartōes com baixo número de créditos a preços equivalentes à mesma 
quantidade de fichas telefônicas. A substituição de fichas telefônicas por cartões também proporciona uma redução considerável nos custos operacionais do serviço. $O$ trabalho de recolhimento, lavagem, embalagem e distribuição de fichas é igual a $50 \%$ do custo de produção de novas fichas.

- A redução dos índices de vandalismo nos telefones públicos, seja pelo oferecimento de um serviço de melhor qualidade ao usuário, seja pelo não armazenamento de valores em cofres no interior dos aparelhos ou pela tentativa de fraudar o sistema de cobrança. Em função de depredações, a manutenção de telefones públicos gerava, na fase anterior à implantação do sistema TP-Cartão, um custo anual de cerca de US\$ 80 milhões para a TELEBRÁS, recursos que poderiam ser utilizados na melhoria e ampliação da rede de telefonia pública. Dados de junho de 1991 indicavam que do total da planta de telefones a ficha, cerca de um terço por mês encontrava-se fora de serviço.

Além do aspecto social, do ponto de vista tecnológico é necessário um sistema mais versátil, que permita que novos serviços sejam implementados e oferecidos ao usuário do serviço público de telecomunicações, sem que as atuais centrais telefônicas sofram alterações.

Tendo portanto como motivadores a diminuição do custo, a melhoria da qualidade do serviço e o aumento da versatilidade, partiu-se em busca de uma solução tecnológica para os telefones públicos que preenchesse tais pré-requisitos. A TELEBRÁS através do CPqD Centro de Pesquisa e Desenvolvimento iniciou pesquisas com diversas tecnologias: a magnética, cartōes inteligentes (smart-cards) e cartões de memória (memory cards).

A possibilidade de utilização da tecnologia magnética na telefonia pública, apesar de bastante difundida mundialmente, foi eliminada por exigir alimentação local ou baterias para o sistema de cobrança, por estar mais sujeita a fraudes e pelo alto custo de produção do cartão para um número reduzido de créditos. Os cartōes inteligentes e de memória, apresentavam ainda um custo de produção bastante alto para a realidade brasileira.

Pela necessidade social do telefone público, era necessário encontrar uma solução técnica que reduzisse os custos do serviço e, simultaneamente, representasse um avanço tecnológico. Após a análise das tecnologias existentes no mundo, em função da realidade brasileira, chegou-se à conclusão que era necessário o desenvolvimento de uma tecnologia própria. Iniciou-se, então, a pesquisa da tecnologia indutiva.

O cartão indutivo tem um baixo custo de produção que torna viável a produção de cartões com baixo número de créditos, atendendo a população de baixa renda. Com processo de fabricação barato, porém difícil de ser reproduzido, o cartão indutivo apresenta alto grau de imunidade a fraudes, o que o corna adequado ao funcionamento em locais não assistidos.

Um outro avanço trazido pelo novo sistema, embora não exclusivo da tecnologia indutiva, $\dot{e}$ a introdução da supervisão remota da planta de telefones públicos que permite obter informaçōes sobre as condições de operação e utilização dos aparelhos. A introduçāo desta facilidade pode contribuir para a diminuiçāo dos custos de operação, administração e manutenção da planta de telefones públicos.

\section{O SISTEMA TP-CARTÃO}

A concepção do Sistema TP-Cartão é mostrada na Figura 1 .

O Sistema TP-Cartão é composto por trếs partes

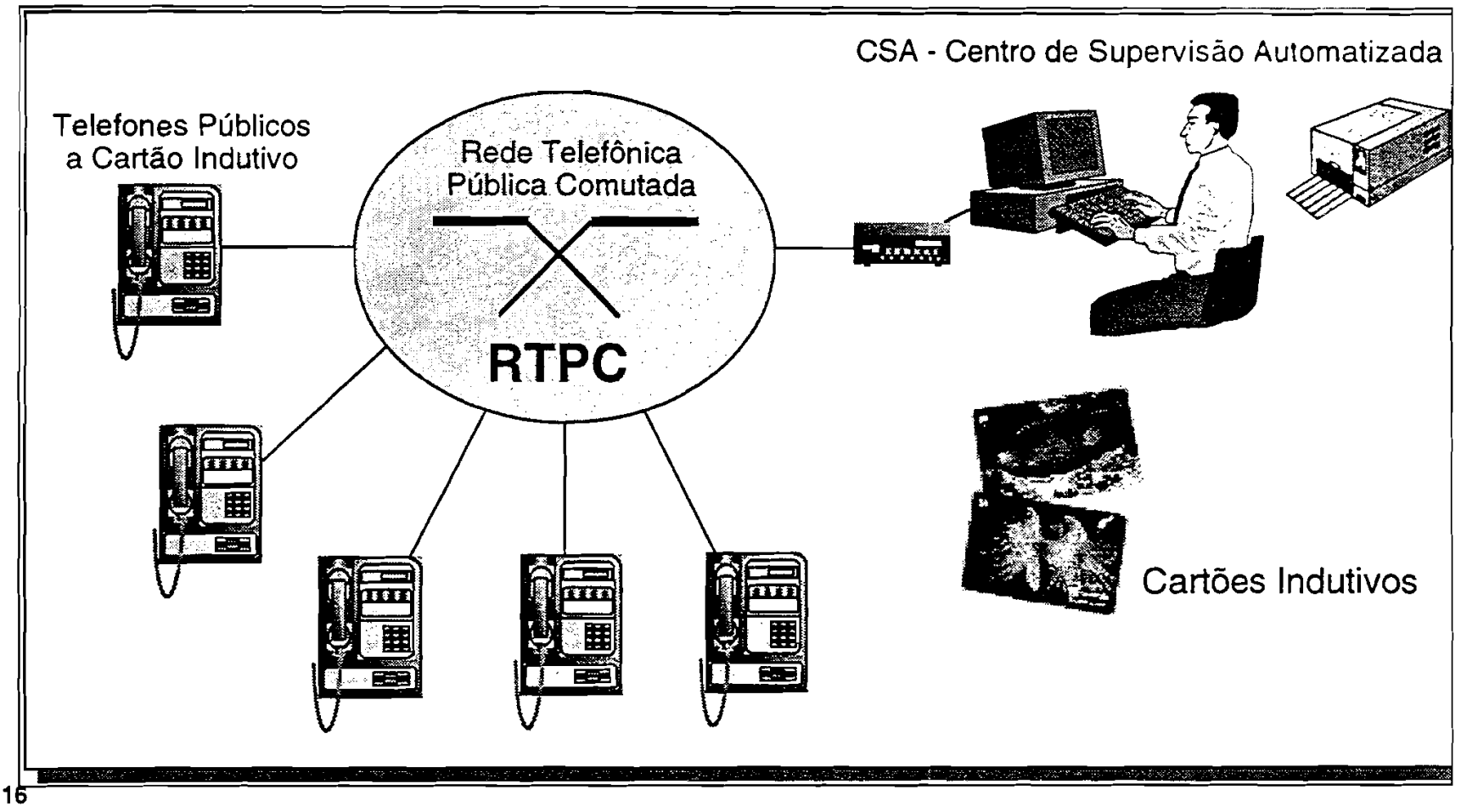


principais:

- terminais TP-Cartão

- cartão indutivo

- Centro de Supervisão Automatizada - CSA

\section{Os Terminais TP-Cartão}

Através dos terminais TP-Cartão o usuário acessa os serviços disponíveis na rede telefônica.

O TP-Cartão é um equipamento moderno, baseado em microprocessador, telealimentado, com diagnóstico de falhas e reportagem automática de falhas e receitas. A característica mais marcante do aparelho é a utilização de cartões e leitoras com tecnologia indutiva, uma patente brasileira desenvolvida para operar sob as características da rede de telefonia pública brasileira. Atualmente o Brasil é o único país a utilizar esta tecnologia em sistemas de telecomunicaçōes

Utilizando circuitos simplificados e mais eficientes, o TPCartão oferece ao usuário um serviço de melhor qualidade que os telefones públicos a ficha. É totalmente eletrônico e sem partes móveis em seu interior, o que permite a redução considerável de peso e tamanho do terminal. Devido às características do cartão indutivo, de leitura estática, não são necessários os mecanismos de tração do cartão ou de coleta e armazenagem. Eliminam-se, ortanto, os principais fatores que contribuem para a -_-zutenção periódica dos aparelhos convencionais.

A utilização de circuitos de baixo consumo permite que o TP-Cartão seja totalmente alimentado pela linha telefônica (telealimentado), dispensando o uso de baterias ou alimentação local.

Funcionalmente, o TP-Cartão pode ser dividido em cinco unidades principais, como mostra a Figura 2:

\section{- Unidade de Controle}

É a principal unidade funcional do TP-Cartão e controla todas as outras unidades. É implementada com o uso de um microcontrolador de 8 bits que, além de permitir um perfeito controle e interfuncionamento das unidades, possibilita que as atualizações de programas ou dados sejam feitas com rapidez e facilidade de implementação. Essa unidade também faz a supervisão de falhas do equipamento e controle da leitora indutiva para leitura e coleta de créditos do cartão indutivo.

O software associado a essa unidade faz o controle de diagnósticos, tratamento de chamadas e o controle de chamadas de supervisão com o CSA.

\section{- Interface Homem-máquina}

Monofone, teclado, leitora de cartões e display são os principais dispositivos de interface com o usuário.

O teclado, a principal entrada de dados do terminal, possui uma saliência na tecla 5 para identificação de posicionamento de teclas por deficientes visuais. As teclas pressionadas pelo usuário são ecoadas para o display que também exibe mensagens que auxiliam no uso do terminal. O teclado também é utilizado durante a instalação do terminal, quando o técnico insere os números que o identificarão.

O usuário acompanha o andamento da chamada pelo display, que fornece informações tais como o número de unidades de crédito restantes no cartão, o número que está sendo chamado, a necessidade de inserção ou troca do cartão, informaçōes sobre o estado de operação do aparelho.

A leitora de cartões, comandada diretamente pela Unidade de Controle, é responsável pela leitura e coleta das

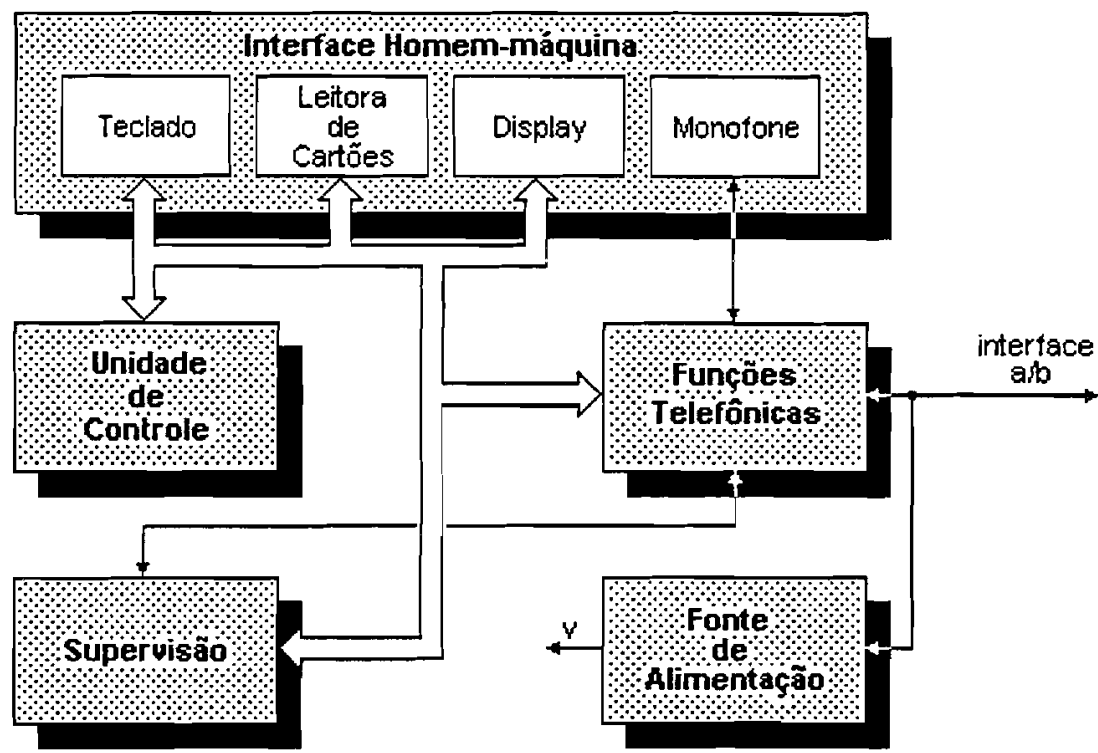

Figura 2 - Diagrama de Blocos do terminal TP-Cartão. 
unidades de crédito do cartão indutivo. $\mathrm{O}$ terminal TPCartão utiliza atualmente somente a leitora indutiva, entretanto pode suportar também uma leitora magnética ou leitoras de outras tecnologias sem alterações significativas no hardware.

O monofone converte sinais elétricos em sinais audíveis e vice-versa, possibilitando a conversação entre dois usuários separados pela rede telefônica.

\section{- Supervisão}

Este bloco é composto por um mođem e sensores de eventos, dispositivos que possibilitam a deteção de falhas e a comunicação do TP-Cartão com o CSA em horários pré-determinados. O modem, padrão ITU-T V.22, opera a $1200 \mathrm{bit/s}$ para a troca de informações com o CSA através da rede telefônica pública comutada - RTPC. O relógio tem a função de disparar o processo de comunicação com - CSA em horários pré-programados, onde são transmitidas as estatísticas de utilização do aparelho. Falhas graves, tais como a abertura não autorizada do terminal ou o rompimento do cordão do aparelho são detetadas pelos sensores de eventos e transmitidas ao CSA em tempo real.

\section{- Funções Telefônicas}

Esta interface implementa as funções telefônicas no equipamento: detetores de pulso de cobrança (por inversão de linha ou freqüência de $12 \mathrm{KHz}$ ), discagem decádica ou multifreqüencial (DTMF), circuito de campainha, híbrida eletrônica e circuitos de proteção.

\section{- Fonte de Alimentação}

Este bloco tem a função de extrair potência da linha telefônica para alimentar os circuitos do terminal TPCartão. Trata-se de um conversor DC/DC de baixa potência e alto rendimento que evita a utilização de fontes de alimentação adicionais tais como rede elétrica ou baterias

\section{O Cartão Indutivo}

Os terminais TP-Cartão utilizam atualmente cartões de débito indutivo, com até 100 unidades de crédito que são coletados no decorrer de uma chamada, seja ela local, regional ou interurbana.

O cartão tem como base um substrato plástico, cujas dimensões obedecem ao padrão ISO (International Standard Organization), de tamanho semelhante a um cartão bancário, sobre o qual são impressos os elementos correspondentes às unidades de crédito, através de um processo foto-químico. O substrato plástico é composto por material plástico flexível $(0.4 \mathrm{~mm}$ de espessura) e reciclável após o término dos créditos do cartão. O cartão, porém, é descartável após o uso, não podendo ser regravado.

O processo de fabricação apresenta baixo custo em relação às outras tecnologias, possibilitando a venda de cartões com poucas unidades de crédito, essenciais para a população de baixa renda. Apesar do baixo custo quando em escala industrial, o processo de fabricação é complexo e sensível a pequenos desvios, dificultando a fraude doméstica.

O cartão indutivo é imune a campos eletromagnéticos dispersos, poeira, umidade, calor e raios ultra-violeta e, por ser simétrico, não necessita de posição específica para inserção na leitora. O processo de leitura e coleta dos créditos do cartão é feito de forma estática e sem contato galvânico entre leitora e cartão.

A tecnologia para produçāo industrial está dominada, sendo atualmente produzido em larga escala. Encontramse disponíveis atualmente cartōes com 100, 90, 75, 50, 35 e 20 unidades de crédito, correspondentes às respectivas quantidades de fichas telefônicas.

\section{- A Tecnologia Indutiva: Cartão e Leitora}

Em substituição ao mecanismo de coleta e armazenagem de fichas dos telefones públicos, foi adotada uma leitora de cartões com tecnologia indutiva.

A leitura e coleta das unidades de crédito baseiam-se no princípio da indução magnética. Na Figura 3 é mostrada isoladamente uma unidade de crédito do cartão e seu respectivo mecanismo de leitura e coleta pertencente à leitora indutiva, cujo modelo se assemelha ao de um transformador elétrico.

A tensão alternada $\mathrm{Vg}$ aplicada ao enrolamento primário

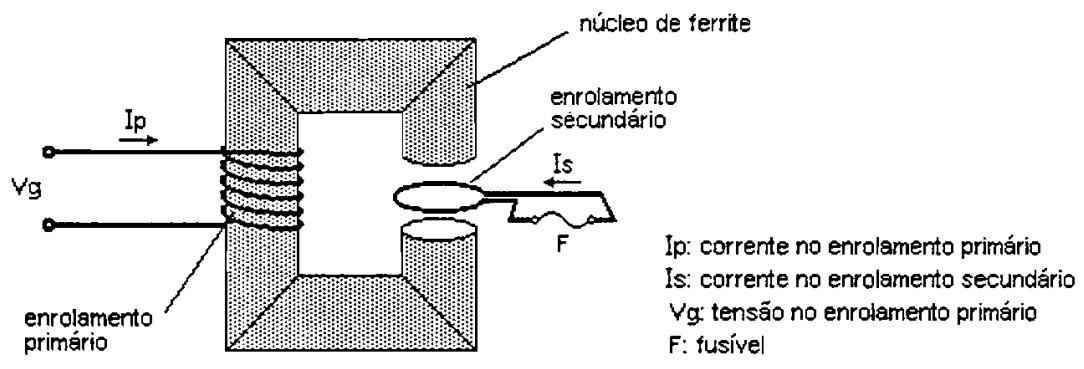

Figura 3 - Modelo da leitora/cartão indutivo. 
do transformador gera um fluxo de corrente Ip que produz, por induçāo, uma corrente Is no enrolamento secundário do transformador. Tendo os parâmetros do transformador bem definidos, a corrente Ip dependerá basicamente da amplitude da tensão $\mathrm{Vg}$ aplicada ao primário do transformador e do estado do fusível $F$. A amplitude da tensão Vg pode ser aumentada de tal forma que a tensão Is seja capaz de aquecer o fusível $\mathrm{F}$ até que este atinja seu ponto de fusão, rompendo-o após um breve período de tempo. O rompimento do fusível $F$ pode ser detetado através de alteraçōes de parâmetros no enrolamento primário.

O cartão indutivo corresponde a um conjunto de enrolamentos secundários/fusíveis impressos sobre 0 substrato plástico, cada qual correspondente a uma unidade de crédito. Os circuitos da leitora indutiva estão associados ao conjunto restante do modelo. Os circuitos da leitora indutiva geram uma tensão e corrente adequados para a verificação do estado do fusível $F$ no cartão; se intacto, considera-se a unidade de crédito não utilizado, se rompido, unidade de crédito já coletado.

A coleta de uma unidade de crédito se faz da mesma forma. A aplicação de tensão e corrente adequados, maiores que no processo de leitura, provoca a indução de uma corrente no enrolamento secundário que aquece e rompe o fusível F. O rompimento do fusível é um processo irreversível, impossibilitando a regravação do cartão e, portanto, reduzindo a possibilidade de fraudes no sistema.

Os processos de leitura e coleta de créditos de um cartão indutivo são realizados de forma estática, sem a movimentação do cartão no interior da leitora e sem contato galvânico entre ambos, eliminando a necessidade de partes mecânicas móveis no aparelho para a movimentação do cartão no interior da leitora ou para a coleta de elementos que validem a cobrança de créditos, reduzindo drasticamente a necessidade de manutenções freqüentes no terminal TP-Cartão.

De todas as etapas do projeto do sistema TP-Cartão, o desenvolvimento do conjunto Leitora e Cartão Indutivos ioi, sem dúvida, a mais importante e a mais trabalhosa. As principais dificuldades encontradas nesta etapa estavam ligadas ao dimensionamento das diversas variáveis das quais dependem o processo de leitura e coleta de créditos do cartão indutivo tais como a geometria adequada dos elementos fusíveis, a geometria da leitora, as proporções dos elementos químicos que compõem o cartão, tensões e correntes corretos para leitura e destruição dos elementos fusíveis, o consumo de potência da leitora, entre outros.

O processo de produçāo industrial do cartão indutivo também deve obedecer rígidos padrões de qualidade tanto na escolha dos elementos químicos que compõem o cartão quanto no processo de impressão das unidades de crédito. Como processo final de verificação da validade dos lotes de cartões, é executado um plano de amostragem e os cartões amostrados são submetidos a uma jiga de testes baseada na própria leitora do TP-Cartão. Atualmente, o processo de produção industrial do cartão indutivo está dominado, com produção mensal de cerca de 30 milhões de cartōes (abril de 1997). Entretanto deverá ainda passar por melhorias visando a redução dos índices de rejeição.

\section{O CSA - Centro de Supervisão Automatizada}

O CSA é responsável pela supervisão remota (telessupervisão) de um conjunto de terminais TP-Cartão instalados em uma determinada região. O sistema CSA é composto por um microcomputador do tipo PC-486 comercial ou versões mais recentes, uma impressora, um modem padrão ITU-T V.22 de chamada/atendimento automático conectado a uma linha comutada de assinante e de um software que opera sobre uma plataforma SCOXENIX $^{\circledR}$ ou DOS-Windows ${ }^{\circledR}$. A comunicação entre o CSA e os terminais TP-Cartão por ele supervisionados se faz através de um protocolo de comunicação proprietário com transmissão de dados à taxa de 1200 bit/s através da RTPC - Rede Telefônica Pública Comutada. O CSA pode supervisionar até 400 terminais TP-Cartão na versão SCO-XENIX ${ }^{\circledR}$ ou 1000 terminais na versão DOS. Windows ${ }^{\circledR}$.

\section{- A comunicação entre terminais TP- Cartão e CSA}

A iniciativa de uma chamada de supervisão parte única e exclusivamente dos terminais TP-Cartão, automaticamente nas seguintes situações:

- em horários programados, determinados pelo CSA, baseados principalmente no horário de início das comunicações, no número de terminais gerenciados e no intervalo de comunicação determinado pelo operador. Neste tipo de comunicação são transmitidos pelo TPCartão dados de receita e utilização, a identificação do terminal, além de estatísticas de pequenas falhas. Como dados de receita, são enviadas informações a respeito da quantidade de unidades de créditos coletadas no período. A quantidade de chamadas locais, interurbanas e de chamadas a cobrar compōem os dados de utilização do TP-Cartão.

- na ocorrência de falhas nos terminais TP-Cartão e que não tenham afetados os elementos envolvidos na comunicação entre terminais e CSA como, por exemplo: a abertura não autorizada do terminal, o rompimento do cordão do monofone, falhas na leitora de cartões, entre outras. A transmissão destes dados ocorre imediatamente após a sua deteção.

- solicitação via teclado durante a instalação ou manutenção dos terminais TP-Cartão. Para que um TPCartão esteja ativo no sistema, ele primeiro deve ser cadastrado no CSA pelo operador e posteriormente instalado por um técnico que realiza no terminal o procedimento de instalação. O procedimento de instalação é feito através da comunicação entre o terminal TP-Cartão e o CSA. Nessa comunicaçāo, o CSA transmite ao TP. Cartão os horários pré-determinados de comunicação. 
data e hora atuais (para que o TP-Cartão possa se sincronizar com o sistema), o número da linha telefônica a qual o CSA está conectado, o número máximo de tentativas de comunicação com o CSA e a periodicidade de comunicação. No sentido TP-Cartão para o CSA, sāo enviados a identificaçāo do TP e a identificação do técnico que o instalou. Se o procedimento de instalação for bem sucedido, o TP-Cartão inicia o armazenamento das informações no período para, no seu próximo horário pré-determinado, enviar todos os seus dados ao CSA.

Se, por acaso um usuário estiver utilizando o TP-Cartão no momento definido para a comunicação, esta será reprogramada automaticamente para uma nova tentativa no próximo horário pré-determinado.

\section{- A interface hornem-máquina}

O sistema CSA é funcionalmente dividido em diversos módulos de programa que se interagem através de trocas de mensagens. Dentre estes, a interface de Comunicaçāo Homem-Máquina cria uma comunicação amigável entre o CSA e seus operadores. O ambiente CSA é composto de um menu principal e de uma série de janelas que possuem funções associadas a elas. Através desta interface o operador pode gerenciar os parâmetros de configuração do CSA, fazer o controle de operaçōes do sistema, controlar a inclusão e exclusão de um terminal TP-Cartão da planta, alterar dados de identificação dos terminais, programar e emitir relatórios configuráveis após um período de comunicação, fazer o "backup" ou cópia de segurança da base de dados, entre outros.

O produto final do CSA são relatórios configuráveis, consolidados a partir dos dados recebidos da planta de TPs. A partir da análise destes relatórios, mecanismos de manutenção ou de remanejamento poderão ser rapidamente acionados com base na receita e utilização dos terminais TP-Cartão.

O CSA funciona em um ambiente multitarefa, isto é, executa todas as suas funções independentemente da tela atualmente em uso, ou seja, não importa em que tela o sistema esteja atuando, ele continuará a receber comunicaçāo dos TPs, imprimirá relatórios, executará "backups" automáticos, etc.

\section{A IMPLANTAÇÃO DO SISTEMA TP-CARTÃO NA REDE DE TELEFONIA PÚBLICA BRASILEIRA.}

A implantação do Sistema TP-Cartāo na rede de telefonia pública brasileira pode ser dividida em duas fases:

- teste piloto

- implantação comercial

\section{- Teste piloto}

O primeiro protótipo ¿̇ lè.è̃za público a cartão indutivo foi concluído pelo CPaD - Centro de Pesquisa e Desenvolvimento da TELEBR.́S em 1989 e permitia a utilização de cartões com 50 unidades de crédito. Um lote piloto de terminais TP-Cartão, montados no próprio $\mathrm{CPqD}$, foi instalado e testado em diversas localidades brasileiras buscando conhecer a opinião de usuários e operadoras quanto ao novo sistema. Durante o teste os usuários do TP-Cartão responderam questionários apontando críticas e sugestōes para melhorar o sistema. $\mathrm{O}$ mesmo procedimento foi adotado para as operadoras que participaram do teste.

As opiniões de usuários e operadoras foram fundamentais para a evolução do sistema em suas características operacionais, funçōes básicas e interface homem-máquina. Podemos destacar como sugestões das operadoras: cartão/leitora com 100 unidades de créditos, display no painel do TP-Cartão, supervisão remota, possibilidade de recepção de chamadas.

Das sugestōes de alteração dos protótipos do TP-Cartão 50 créditos, iniciou-se o projeto $\mathrm{TP}-100 / \mathrm{S}$ visando aumentar o número de unidades de créditos do cartão/leitora para 100 e incorporando a supervisão remota ao sistema. $\mathrm{O}$ projeto foi desenvolvido pelo $\mathrm{CPqD}$ juntamente com as empresas fabricantes de telefones públicos. O teste piloto do TP-100/S ocorreu inicialmente no Rio de Janeiro, tendo início em março de 1992, com a instalação de 19 terminais TP-Cartão e a distribuição de 2870 cartões de 100 unidades de crédito. O Sistema TPCartão ainda não apresentava a supervisão remota. Os questionários respondidos pelos usuários relataram que o TP-Cartão superava qualitativamente o TP a ficha, destacando como vantagens a praticidade e portabilidade de altos valores em créditos (até 100 unidades) e a qualidade de comunicação, que eliminava o ruído gerado pela coleta de fichas.

Este teste foi estendido aos aeroportos do Galeão e Santos Dumont no Rio de Janeiro ainda com a participação dos usuários e com acompanhamento da operadora local. A primeira fase de testes foi concluída em maio de 1992 com os terminais TP-Cartão atendendo satisfatoriamente aos requisitos técnico-operacionais.

\section{- Implantação comercial}

O Sistema TP-Cartão entrou em operação comercial inicialmente no Rio de Janeiro, durante o evento internacional ECO 92 (RIO 92) com um lote-piloto de 400 terminais TP-Cartão e 3 CSAs. Estes equipamentos foram testados e instalados com a participação de técnicos do CPqD-TELEBRÁS, da operadora local e das indústrias fabricantes de telefones públicos.

Os terminais TP-Cartão foram instalados em aeroportos, nos principais pontos turísticos e no Riocentro (centro de convençōes que sediava a conferência). O desempenho dos terminais era acompanhados pelos CSAs que controlavam a situação da planta, orientando as equipes 
de manutenção e inspeção. Durante esta fase foram comercializados mais de 33 mil cartões telefônicos com $10,50,100,400$ e 800 créditos, sendo que os de 400 e 800 realizavam chamadas internacionais e circularam somente durante o evento. Os cartōes telefônicos eram supridos por uma linha piloto montada no CPqDTELEBRÁS. O processo de impressão gráfica dos cartões ficou a cargo das futuras empresas fabricantes de cartões, ainda em fase de engajamento no projeto. Durante este periodo, observou-se que a receita média mensal por aparelho passou de US\$ 50 do TP a ficha para US\$ 150 do TP-Cartão e que o índice de falhas ou de vandalismo tornou-se bastante reduzido.

No final de 1992 e início de 1993, foi lançado o "Programa de Disseminação da Tecnologia do Cartão Indutivo" quando várias outras empresas operadoras receberam temporariamente terminais TP-Cartão para a assimilação da nova tecnologia. A supervisão destes terminais era realizada por um CSA instalado no CPqDTELEBRÁS, muitas vezes a milhares de quilômetros de distância.

Devido aos resultados positivos alcançados até 0 momento, passou-se para a fase de ampliação da planta de terminais TP-Cartão a nível nacional e as empresas fabricantes de cartões indutivos passaram a implantar suas próprias linhas de produção, sob a supervisão do $\mathrm{CPqD}$ TELEBRÁS, atendendo a crescente demanda de consumo de cartōes.

O custo médio anual de um telefone público a cartão já é US\$ 24 menor que de um telefone público a fichas, tendendo a diminuir diante do ritmo crescente da demanda de operadoras e usuários. Em

abril de 1997 estavam em operação 206 mil terminais TPCartão e a produção mensal de cartões atingiu a marca de 30 milhōes de unidades. Quando comparado com telefones a ficha, os custos de operação e manutenção diminuíram por um fator de quatro (as taxas de reparos cairam de $33 \%$ para $8 \%$ ), o preço de aquisição de novos terminais reduziu à metade e a taxa de utilização dos aparelhos dobrou. (Fonte: DCOS - Diretoria de Coordenação e Serviços - TELEBRÁS - Brasília).

\section{O FUTURO DO SISTEMA TP. CARTÃO}

O Sistema TP-Cartão já é uma tecnologia consagrada e está presente no dia a dia dos brasileiros. Os resultados obtidos desde o início dos testes até o momento têm confirmado as expectativas, com alto grau de satisfação dos usuários.

Diante deste retorno, a TELEBRÁS pretende substituir todos os telefones públicos a ficha pelo novo modelo até o final de 1998. A expansão da rede de telefonia pública também está nos planos da empresa. A meta para o ano 2000, segundo o PASTE - Plano de Recuperação e Ampliação do Sistema de Telecomunicações e do Sistema Postal - é de 800 mil telefones públicos espalhados pelo
Brasil, com uma produção de cartões estimada em 1 bilhão de unidades anuais.

Porém, a expansão da telefonia pública no futuro deverá incorporar novos avanços tecnológicos, tendo como objetivos principais:

- a redução do custo dos terminais, de serviços, de operação, administração e manutenção da planta de telefones públicos.

- introdução de novos serviços e facilidades.

- aumento da confiabilidade (qualidade) do sistema.

Neste contexto, o Sistema TP-Cartão e seus componentes poderão evoluir da seguinte forma:

\section{- na tecnologia de cartões e leitoras}

- otimização do processo de produção do cartão indutivo, visando 0 aumento da qualidade e redução do custo.

- codificação do cartão indutivo para aplicações em serviços de crédito, que envolvam acesso a senhas e bancos de dados, desde que a rede ofereça os meios de proteção necessários.

- padronização da interface de dados da leitora indutiva, tornando-a compatível com qualquer sistema baseado em microprocessador. As aplicações para o cartão/leitora indutiva são ilimitadas.

- "dual-technology" - desenvolvimento de terminais e leitoras capazes de operar com outras tecnologias além da indutiva como, por exemplo, as tecnologias magnética, óptica e "chip-card" (smart e memory-card), flexibilizando a introdução de novos serviços. Como exemplo ilustrativo, imagina-se oferecer o serviço telefônico com a tecnologia indutiva e aplicações multi-serviços com a tecnologia "chip-card" num único terminal público. Há tendências para o predomínio da tecnologia "smart-card" no futuro, porém em países em desenvolvimento será necessária a coexistência com uma tecnologia mais barata para que a população de baixa renda continue tendo acesso aos serviços básicos.

\section{- no aparelho telefônico}

- autotarifação - consiste em retirar a função de tarifação da central e implantá-la no terminal TPCartão. A cadência de coleta de unidades de crédito é controlada pelo terminal, baseada em tabelas de tarifação armazenadas em memória. Estão em fase de estudos as formas de transferência destas tabelas para o terminal através da rede.

- sintese de voz - mensagens geradas localmente auxiliarão o usuário no uso do terminal durante o estabelecimento de uma chamada ou alertando-o para a ocorrência de uma falha. As amostras de voz poderão ser armazenadas em memória e atualizadas através da rede.

- redução de custos, dimensões e consumo de potência dos terminais - Utilização de circuitos 
integrados dedicados e da tecnologia de montagem de superfície (SMD) terão como consequiências imediatas a redução do custo, dimensões e consumo do terminal, além do aumento da confiabilidade dos circuitos. Atualmente o TP-Cartão utiliza dois circuitos integrados desenvolvidos no CPqD-TELEBRÁS: o TB-24 (híbrida eletrônica) e (controlador de interrupçōes, desenvolvido especificamente para o projeto). Outros dois circuitos integrados estão em fase de desenvolvimento e deverão ser incorporados ao TP-Cartão: o TB-38 (osciladores e multiplexadores para a leitora indutiva) e o TB39 (avaliador de estados da linha telefônica).

- RDSI (Rede Digital de Serviços Integrados) Com o advento da RDSI, a leitora indutiva poderá ser facilmente acoplada a um terminal digital, transformando-o em um terminal público RDSI a cartão indutivo. Além do serviço de voz, o usuário poderá ter acesso a inúmeros serviços que envolvam a transferência de dados a taxas não disponiveis atualmente na rede telefônica. $\mathrm{Na}$ RDSI o sistema fica ainda mais seguro devido à facilidade de implementação de novos métodos de cobrança em um canal exclusivo de sinalização digital.

\section{- no CSA}

- O CSA como componente de TMN Telecommunications Management Network Por suas características de supervisāo de receitas, utilização e falhas, pode-se dizer que o Sistema TP-Cartão já incorpora as camadas mais baixas do modelo TMN. É necessária, portanto, a implementação de uma "porta de saída" dos dados gerenciados pelo CSA para uma hierarquia superior através de um protocolo padronizado (Qx/Q3).

\section{- no Sistema TP-Cartão}

- Desenvolvimento de sistemas inteligentes que incorporem funções de tarifação e multiplicação de terminais por par metálico possibilitarão a expansão da planta de telefones públicos com investimentos reduzidos. A função de multiplicação é obtida graças às novas técnicas de codificação, multiplexação e transmissão digitais, através dos quais vários canais de voz poderão ser transmitidos simultaneamente em um único par metálico. A aliança destas técnicas à autotarifação permitirá o surgimento de sistemas autônomos que retirariam a função de tarifação das centrais telefônicas e possibilitarão a transmissão de vários canais de voz provenientes de terminais TP-Cartão em um único par metálico, aumentando a versatilidade do sistema de telefonia pública.

\section{CONCLUSÃO}

A tecnologia de cartões indutivos aplicada à telefonia pública deixou de ser um simples objeto de pesquisa para fazer parte do dia-a-dia da populaçāo brasileira. Este fato só ocorreu em decorrência da constatação de que a tecnologia indutiva atendia efetivamente às peculiaridades da sociedade brasileira e sua planta de telefonia pública. Embora existam sistemas mais sofisticados, o desempenho apresentados por estes sistemas pode diferir de região para região de instalação devido às diferenças econômicas e culturais. Portanto, ao desenvolver uma tecnologia, é necessário conhecer as características da sociedade onde ela será implantada, sob o risco de nāo atendê-la efetivamente. O Sistema TP-Cartāo tem despertado o interesse de diversos países cujas características socioeconômicas são semelhantes à brasileira.

Em um futuro próximo, toda a planta de telefones públicos no Brasil estará utilizando a tecnologia indutiva, evoluindo com a implementação de novos serviços além da telefonia básica, dada a versatilidade do sistema e a aplicação de novas tecnologias.

A conjugação de qualidade, desempenho e baixos custos parece ter sido atingida graças à tecnologia aplicada às necessidades regionais.

\section{AGRADECIMENTOS}

Esse artigo teve a colaboração de parte da equipe de desenvolvimento do projeto TP-Cartão:

Antonio Massao Nishikawa, Ênio Calçavara Júnior, Heliete de Almeida Lins Leitão. Manuel Augusto M.S. Pato, Marcos Aurélio Pegoreti, Maristela Domeni Navarro, Osvaldo de Queiroz Makishıma, Paulo Henrique de Oliveira Lopes.

Marcos Assano é formado em Engenharıa Elétrica pela Universidade Estadual de Campinas. em 1988. c Trabalha no CPqD - Centro de Pesquisa e Desenrolvimento da Telebrás, desde 1988, na área de termınass. Aluou em projetos de desenvolvimento de termunas RDSI e terminais a cartão indutivo. Alualmente trabalha na prospecção de novos serviços baseados em cartāo telefônico indutivo. 